\title{
Reflections on research at the College of Medicine: Excellence yesterday, today, tomorrow
}

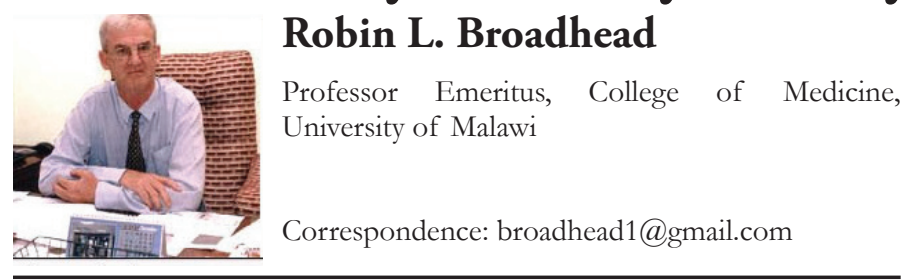

\section{The etymology of "research"}

Research! I have often pondered on the word that we use for investigating the wonders of our world. "To search", yes, I can understand that, but to research implies that we are reviewing what we already know. And often that is perhaps what we often do. So that is where I will start.

Many of the questions that we pose to our ignorance have implicit in them the answers that we anticipate. The way we phrase things determines often the outcome we expect, because our objectivity - even at its most naked - is rooted in our subjectivity as the individual researcher. This is not willful prejudgement or prejudice but an intrinsic bias rooted in our previous cultural and research history. But research, it may be argued, is often a collaborative effort. Surely collective enquiry frees the individual to be objective and unconfined by the bias of the subjective? Not so-I would suggest that a plurality of researchers starts with a premise to which they will all agree to sign up under the principal investigator.

However, knowing this does not invalidate the enquiry. And the enquiry itself is a noble quest. It hinges on another word. The quest (by the process of questioning) is to seek to understand what is at the heart of science and medical research. There is value in the asking-the quest for knowledge. It is the same with the posed problem that is an invitation to probe. The process of probing may lead to an illumination, not necessarily to an answer.

Why this lingering on the etymology of words? Because it has always seemed to me that research has to begin with accepting the constraints of attitude (the attitude of the researcher). There is a need to subsume the individuality of the researcher from personal ambitions that often obscure the clarity of vision. This means that a certain humility in the search for understanding is required for there to be a real advancement in knowledge in health and disease.

Where is this leading? It is leading to all our yesterdays in our recognition that the great corpus of medical knowledge is rooted in the past. Our current understanding is founded on the shoulders of observant researchers long before Hippocrates and those who have come after.

We have to admit our indebtedness to the many who have added to the body of medical knowledge- this accumulation from so many different interests and experiences. From medieval Persia and the brilliant observations of Rhazes and Avicenna; to the great enquiring minds of Leonardo da Vinci and Michelangelo of the Italian Renaissance; through to the meticulous recording by Rembrandt in his painting The Anatomy Lesson of Dr. Nicolaes Tulp; and finally on into the modern era of Joseph Lister, Francis Crick and James Watson, and Christiaan Barnard. We should recongise such contributions with gratitude and inspiration. This is where all our yesterdays have led us.
Our yesterdays have led us to today, where we appear to be on the threshold of a revolution in the way we address the questions of the interactions between the environment and individual prophetic genetic propensities. It is the age of large-scale population studies, of teams of researchers employing the power of the computer to balance the many variables and complexities that emerge from modern longitudinal studies.

Indeed, it is the longitudinal study over years (rather than weeks and months) and the significance of the computer to compress time to almost instantaneous analysis that have opened up new vistas of what constitutes health and disease. It is becoming apparent that most new insights are coming from long-term observations of populations. The new discipline of epigenetics is beginning to influence our thinking. This is where the old dichotomy between Darwinism and Lamarckism resolves into a fascinating discussion of the interaction between the environment and genes. This conversation is producing new insights that are to do with who we are and how we can change. It is indeed the study of change.

It should be no surprise that, as a paediatrician, I am interested in growth and change. From conception to the five-year-old child, the wonderful changes that constitute human growth have their echoes of phylogeny: the past influencing the present and the future. It was the late David Barker, epidemiologist at the University of Southampton, who hypothesised that adverse in utero conditions influence the developing foetus to adapt for survival. The environment caused genes to express themselves in ways that later produced effects in the growing child and into adulthood. These insights have to be tested. This is best done through long-term longitudinal studies of stable populations. For example, the Karonga Prevention Study (now the Malawi Epidemiology and Intervention Research Unit, MEIRU), initially set up over 35 years ago by Professor Paul Fine of the London School of Hygiene and Tropical Medicine, aimed to, amongst other things, study the effects of BCG at birth on the future prevalence and incidence of tuberculosis in the community. Unexpectedly, the vaccine was found to have a profound protective effect against leprosy and, over a decade, almost eradicated the disease from Malawi.

The stated philosophy of research at the College of Medicine has always been that the research conducted should be concerned with addressing the health problems and diseases of Malawi. This is an intention that sounds ethically and politically correct but is actually nonsense. I say this because global health problems such as HIV/AIDS, malaria, and childhood malnutrition remain intractable from one cultural context to another. Hence, answers to local problems can have global significance. In addition, the scientific questions, methodologies, and implementation processes are the same and demand the same high standards of surveillance wherever in the world research is conducted. True, special consideration has to be given to illiterate and vulnerable populations, but the process and conduct of investigation is the same. This global approach to research has led to an enrichment of the academic environment at the College of Medicine. 
One of the important policies that the College of Medicine adopted from its beginning was to actively seek partnerships and collaborations with other academic centres of excellence. This has been fruitful in many ways. It has allowed for research groups to develop and long-term studies to be conducted. It has fostered Malawian research fellows into career pathways in medical science. It has enriched undergraduate medical education at the College through an obligation that research fellows (both international and local) give at least 30\% of their time to teaching duties in the various departments of the College to which they are assigned.

The College can boast of hosting research affiliations that are leading in many internationally important areas of medical research. They include the Blantyre Malaria Project, the Johns Hopkins Project, the Malawi-Liverpool-Wellcome Trust Clinical Research Programme, the Malaria Alert Centre, and other research groups based at department levels. This is all to the good, but one of the aspects of some medical research is what I call research revisited.

\section{Research revisited}

There is a perception among many young doctors that there is a need for all doctors to have to do some research and "publish or perish". This attitude is often fostered during undergraduate medical training. It suggests that the enquiring mind is not enough and that if there is not some evidence of research then the advancement and career opportunities will be limited.

This is unfortunate. Not all those who wish to do medicine are interested in the process of research, however welcoming they can be of the advances that research brings. Many doctors wish to practice physic and yet feel compelled to do some research. This can often lead to a great deal of repetition and studies for knowledge already well known.

I have noted this particularly in the field of childhood malnutrition. There is much data and many studies on the risk factors and clinical consequences of malnutrition in early infancy. But still there are a multitude of clinical and epidemiologic studies that merely reconfirm the results of former studies. Much of the data are merely clinical auditseasily accessible and not difficult to interpret. We know so much about the effects of acute and chronic malnutrition, and the associated epidemiology, clinical presentations, and management, yet the information rarely translates into political action, remedial policy, or a social will to address the causes.

Malnutrition is not a disease. It is a consequence of poverty and deprivation. We have known this for decades. Research has shown that severe malnutrition causes long-term cognitive and physical consequences, particularly in growing children. In my view, the health professions have not been vocal enough to challenge the financial and social systems that perpetuate this. Instead, more research is done, with very little of it making a major contribution to alleviating the problem.

Research that leads to clear conclusions about advances in patient management should ethically be introduced as best practice as soon as possible. And here we come to what I call the implementation gap. This is a mismatch between what we know to be effective and what we fail to implement.

\section{The implementation gap}

There was something of a sensation when, in 1997, the New England Journal of Medicine published an article titled, "Unethical trials of interventions to reduce perinatal transmission of the human immunodeficiency virus in developing countries", with an accompanying editorial., ${ }^{1,2}$ The authors reported that certain studies being conducted in Africa were on vulnerable populations living with HIV and AIDS. These where populations in which the prevalence of HIV infection was high but literacy was low, in the context of poverty and poor access to health services. It was argued that, because subjects in some of the countries where trials were being conducted were not able to access treatments that were known to be effective and best practice, these treatments were not offered to them.

This welcome exposure of the implementation gap, between the knowledge already available from research and the treatments that could be offered, caused a great deal of soul searching. It was a catalyst for many academic centres in Africa and elsewhere in the developing world to create bioethics committees to scrutinise research projects.

From its inception, the College of Medicine already had a research committee in place to assess research proposals: the College of Medicine Research and Ethics Committee, (COMREC). COMREC had been granted the mandate to approve or reject any research proposal submitted by the National Research Council of Malawi. Together, with its sister committee, the National Health Sciences Research Committee (NHSRC), COMREC was granted a right to approve or reject research proposals submitted to it. However, in the light of the controversy that had erupted after the publication of the New England Journal of Medicine article, the College felt obliged to address the ethical probity of all research submitted and was encouraged by the appointment of Prof. Joseph Mfutso-Bengo, a Malawian bioethicist of experience. He set about creating a regional centre for bioethical training in research (Centre for Bioethics in Eastern \& Southern Africa, CEBESA) and redefined the local committee as COMREC. The College has every reason to be proud of this initiative and the example it has set.

Finally, medical research can bring out the best and sadly sometimes the worst in us. I have observed how medical research can be the cause of conflict through fierce competitiveness. Ambition to be the best in one's chosen field can distort judgement and cause good research to be shelved and trials to be abandoned. Petty personal grievances have been subsumed even in research committees which should be the guardians against such prejudice. This is not often admitted and, unfortunately, is not uncommon.

So what's in the word "research"? There is much, I would submit. There is yesterday's knowledge to build on for today's questions. Then there is the search itself-the journey and the quest towards the excitement of a future discovery. Research is intrinsically orientated to the future; to the tomorrow.

\section{References}

1. Lurie P, Wolfe SM. Unethical trials of interventions to reduce perinatal transmission of the human immunodeficiency virus in developing countries. N Engl J Med. 1997 Sep 18;337(12):853-6.

2. Angell M. The ethics of clinical research in the Third World. N Engl J Med. 1997 Sep 18;337(12):847-9. 